\title{
Quantitative Analysis of DNA-Mediated Formation of Metal Nanocrystals
}

\section{Supporting Information}

Yiming Wang, ${ }^{\dagger}$ Michael J. Counihan, ${ }^{\dagger}$ Jeffrey Wayjer Lin, ${ }^{\dagger}$ Joaquín Rodríguez-López, ${ }^{\dagger}$ Hong Yang, *†, ${ }^{*} \mathrm{Lu}^{*}, \dagger$

Departments of Chemistry ${ }^{\dagger}$ and Chemical and Biomolecular Engineering, ${ }^{\star}$ University of Illinois at Urbana Champaign, Urbana, Illinois 61801, United States

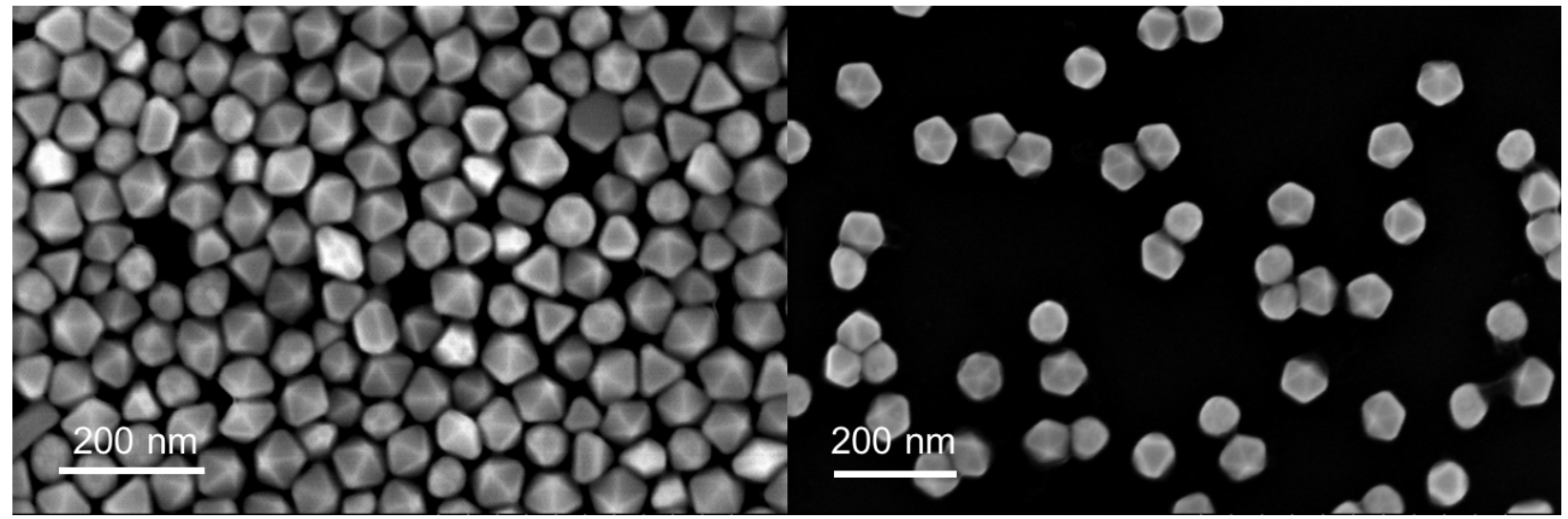

Fig. S1: SEM images of Au decahedra seeds.

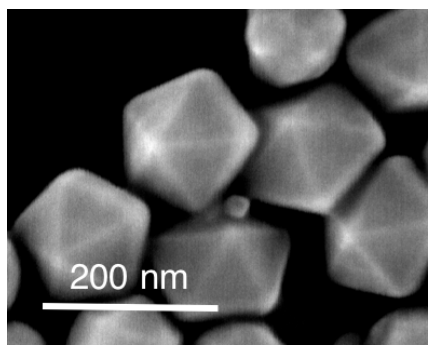

Fig. S2: SEM image of the products of $\mathrm{Ag}^{+}$reduction on $\mathrm{Au}$ decahedra seeds with $\mathrm{G} 20$.

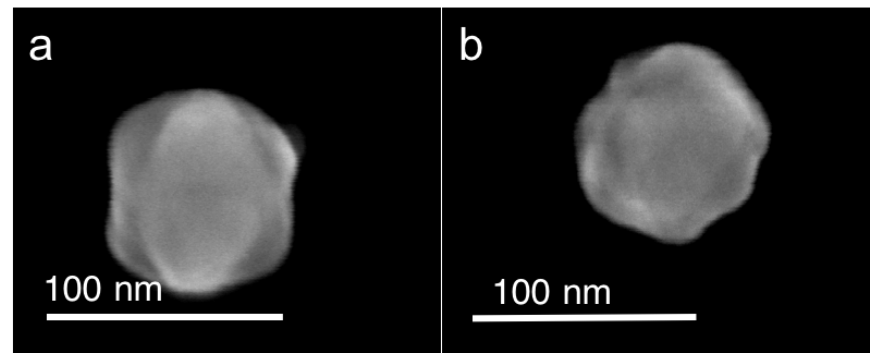

Fig. S3 SEM images of Au-Ag nanostructures grown with A20 from different directions. (a) Parallel to the equatorial plane (b) a slanted angle between perspective in (a) and that of the fivefold symmetrical axis. 

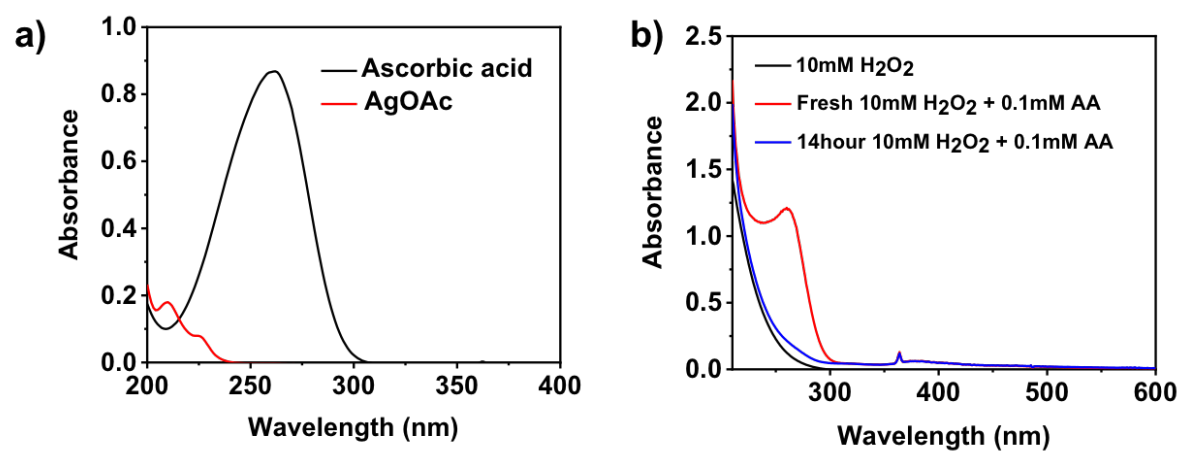

Figure S4. UV-vis absorbance of a) ascorbic acid (100 $\mu \mathrm{M})$ and $\mathrm{AgOAc}(200 \mu \mathrm{M})$ and b) ascorbic acid oxidized by $\mathrm{H}_{2} \mathrm{O}_{2}$.
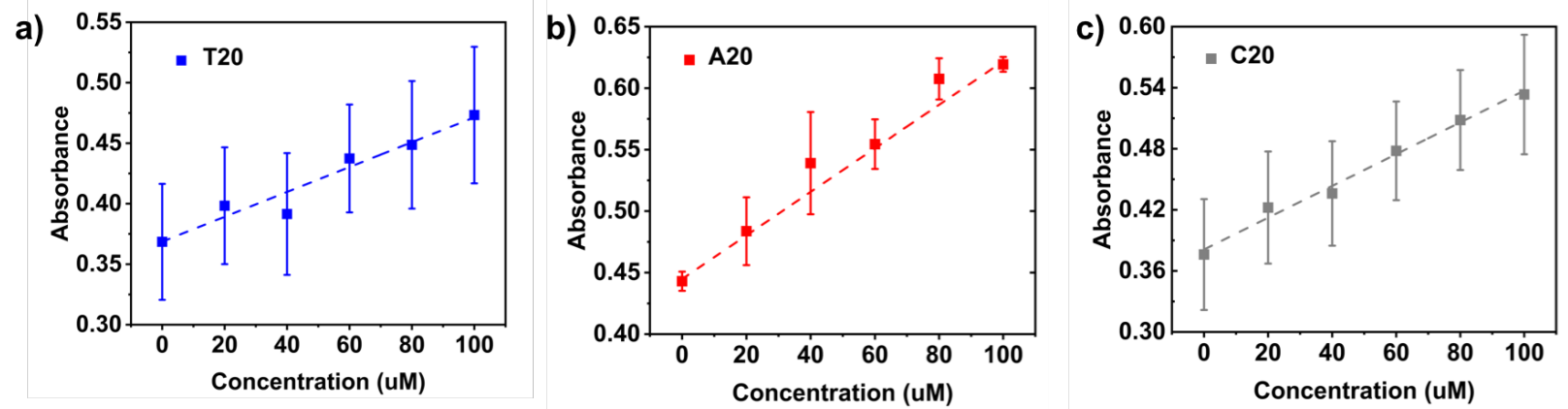

Figure S5. Calibration curve of UV-vis absorbance at $266 \mathrm{~nm}$ as a function of concentration of ascorbic acid. 


\section{SI Note 1.}

Spectroscopic measurement of ascorbic acid concentration

As shown in Fig. S4a, ascorbic acid has signature peak at $266 \mathrm{~nm}$, and this peak does not overlap with that of AgOAc. From Fig. S4b, the oxidized product of ascorbic acid does not have absorbance at $266 \mathrm{~nm}$. Therefore, the absorbance change in $266 \mathrm{~nm}$ in the reaction solution could only be induced by the change in the concentration of ascorbic acid. Another possible complication is that most of the DNA has absorbance at $266 \mathrm{~nm}$. Because DNA is not being consumed during the reduction process, we consider the absorbance contribution from DNA is a constant throughout the reduction process, which was subtracted to retrieve the absorbance from ascorbic acid alone. Considering the complexation between DNA and $\mathrm{Ag}^{+}$might induce some changes to the absorbance of the DNA, for each point in the calibration curve (Fig. S5), we added the stoichiometry ratio (1:2) of ascorbic acid and $\mathrm{Ag}^{+}$together with $20 \mu \mathrm{M}$ DNA to simulate the actual complexation condition in the reaction solution, so the minor change in DNA peak induced by $\mathrm{Ag}^{+}$could be mitigated. The absorbance of reaction solution without preformed seed was directly measured in a cuvette that is $1 \mathrm{~mm}$ in path length. Aliquot was taken from reaction solution with preformed seed at certain time points, and centrifuged at $8 \mathrm{k} \mathrm{rpm}, 2 \mathrm{~min}$ to remove nanocrystals. The absorbance of resulting supernatant was measured. Absorbance was converted to the concentration of ascorbic acid using the calibration curve.

\section{Effect of oxidation of ascorbic acid by oxygen}

Ascorbic acid can react with both $\mathrm{Ag}^{+}$and oxygen in air. We thus analyzed and decoupled the reaction between ascorbic acid and oxygen to accurately determine the reaction kinetic between $\mathrm{Ag}^{+}$and ascorbic acid. The change of concentration of ascorbic acid in air without $\mathrm{Ag}^{+}$precursor was measured as the control experiment. The concentration of ascorbic acid solution $(100 \mu \mathrm{M})$ was monitored in the same container used for the synthesis by the UV-vis spectroscopic method. As shown in Fig. S7, the concentration of ascorbic acid was only decreased by $7 \%$ after $25 \mathrm{~h}$. Therefore, for reactions much shorter than $25 \mathrm{~h}$, the ascorbic acid consumption by oxygen is negligible. The only reaction that has similar timescale as that of ascorbic acid decay is C20mediated reduction with seed (SI Note 8). However, even in this case, the contribution of oxygen oxidation of ascorbic acid is less than $10 \%$ (9.27\%) of the total consumption of ascorbic acid by the reduction reaction.

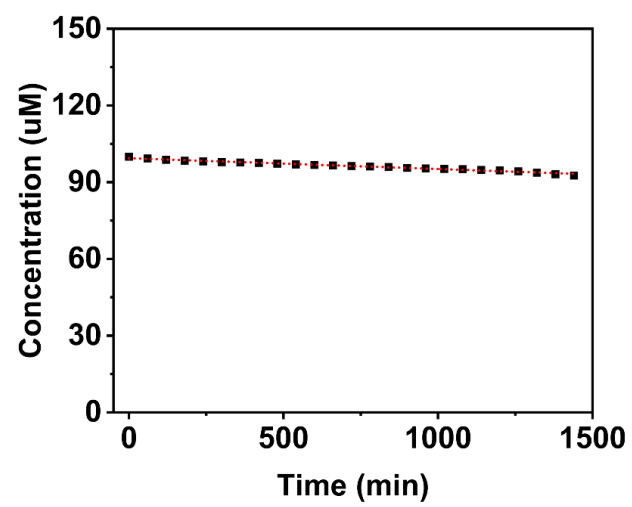

Figure S7. Concentration of ascorbic acid solution in air as a function of time. The initial concentration was $100 \mu \mathrm{M}$. 
Regardless, in the following analysis, [red] has been calibrated prior to curve fitting by subtracting the ascorbic acid consumed by air for an accurate estimation of reaction rate between $\mathrm{Ag}^{+}$and ascorbic acid.

\section{SI Note 2}

Notice that equation (6) and (8) are pseudo-elementary step, ${ }^{1}$ each of which might include more steps in the actual reaction. For example, the reaction between $\mathrm{Ag}^{+}$and $\mathrm{AA}$ involves at least the following two steps: ${ }^{2}$

$$
\begin{array}{lr}
\mathrm{AH}_{2} \leftrightarrow \mathrm{AH}^{-}+\mathrm{H}^{+} & \text {fast } \\
\mathrm{AH}^{-}+\mathrm{Ag}^{+} \rightarrow \mathrm{AH} \cdot+\mathrm{Ag}^{0} & \text { slow }
\end{array}
$$

The second step is rate limiting. As a result, in the rate expression (7) and (9), the reaction order is one for both $\mathrm{Ag}^{+}$and $\mathrm{AA}$. Using pseudo-elementary step to analyze complex kinetic mechanism has previously being demonstrated. ${ }^{2}$

\section{SI Note 3}

T20-mediated $\mathrm{Ag}^{+}$reduction without preformed seed: two step analysis

$-\frac{d[R E D]}{d t}=k_{1}\left[\mathrm{Ag}^{+}\right]_{\mathrm{eq}}[\operatorname{Red}]+k_{2}\left[\mathrm{Ag}^{+}\right]_{\mathrm{eq}}[\operatorname{Red}]\left[\operatorname{Ag}_{\mathrm{n}}^{0}\right]$

$\left[\mathrm{Ag}^{+}\right]_{\mathrm{eq}}=\frac{\left[\mathrm{Ag}^{+}\right]_{\mathrm{t}}}{1+\mathrm{K}_{\mathrm{eq}}[\mathrm{base}]_{\text {eq }}^{2}} \quad\left(\left[\mathrm{Ag}^{+}\right]_{\mathrm{t}}\right.$ is the total $\left[\mathrm{Ag}^{+}\right]$in the solution at time $\mathrm{t}$ after the reaction started)

$\left[\mathrm{Ag}_{\mathrm{n}}^{0}\right]=\left[\mathrm{Ag}^{+}\right]_{0}-\left[\mathrm{Ag}^{+}\right]_{\mathrm{t}}\left(\left[\mathrm{Ag}^{+}\right]_{0}\right.$ is the total $\left[\mathrm{Ag}^{+}\right]$at the beginning of the reaction $\left.{ }^{3}\right)$

According to the stoichiometry of the reaction:

$d\left[\mathrm{Ag}^{+}\right]_{t}=2 d[\operatorname{Red}]_{t}$

Initial concentration $\left[\mathrm{Ag}^{+}\right]_{0}=2[\mathrm{Red}]_{0}$

Substituting $\left[\mathrm{Ag}^{0}{ }_{\mathrm{n}}\right]=\left[\mathrm{Ag}^{+}\right]_{0}-\left[\mathrm{Ag}^{+}\right]_{\mathrm{t}}$

$\left[\mathrm{Ag}^{+}\right]_{\mathrm{t}}=2[\mathrm{Red}]_{\mathrm{t}} \quad$ (the subscript $\mathrm{t}$ was omitted in the following equations for simplicity)

$-\frac{d[\text { Red }]}{d t}=k_{1} \frac{2[\mathrm{Red}]}{1+K_{e q}[D N A]_{e q}^{2}}[\operatorname{Red}]+k_{2} \frac{2[\mathrm{Red}]}{1+K_{e q}[D N A]_{e q}^{2}}[\operatorname{Red}] \times 2\left([\mathrm{Red}]_{0}-[\mathrm{Red}]\right)$

Let $k_{1}^{\prime}=\frac{k_{1}}{1+K_{e q}[\text { base }]_{e q}^{2}}, \quad k_{2}^{\prime}=\frac{k_{2}}{1+K_{e q}[\text { base }]_{e q}^{2}}, \quad[\text { base }]_{\text {eq }}=366.10 \mu \mathrm{M}($ SI Note 4 and Table S1)

$-\frac{d[\text { RED }]}{d t}=2 k_{1}^{\prime}[\mathrm{Red}]^{2}+4 k_{2}^{\prime}[\operatorname{Red}]^{2}\left([\operatorname{Red}]_{0}-[\operatorname{Red}]\right)$

$\int_{[\text {Red }]_{O}}^{[\text {Red }]} \frac{d[\text { Red }]}{\left(2 k_{1}^{\prime}+4[\text { Red }]_{0} k_{2}^{\prime}[\text { Red }]^{2}-4 k_{2}^{\prime}[\text { Red }]^{3}\right.}=\int_{0}^{t} d t$

$\mathrm{t}=\frac{2[\text { Red }]_{\mathrm{O}}[\text { Red }] \times \mathrm{k}_{2}^{\prime} \ln \left(\frac{\left(2[\text { Red }]_{\mathrm{O}} \mathrm{k}_{2}^{\prime}\left([\text { Red }]_{\mathrm{O}}-[\text { Red }]\right)+[\text { Red }]_{\mathrm{O}} \mathrm{k}_{1}^{\prime}\right)}{\mathrm{k}_{1}^{\prime}[\text { Red }]}\right)+2 \mathrm{k}_{2}^{\prime}[\text { Red }]_{\mathrm{O}}^{2}+\mathrm{k}_{1}^{\prime}[\text { Red }]_{\mathrm{o}}-\left(2 \mathrm{k}_{2}^{\prime}[\text { Red }]_{\mathrm{o}}+\mathrm{k}_{1}^{\prime}\right)[\text { Red }]}{2[\text { Red }]_{\mathrm{o}}\left(2[\text { Red }]_{\mathrm{o}} \mathrm{k}_{2}^{\prime}+\mathrm{k}_{1}^{\prime}\right)^{2}[\text { Red }]}$

(Equation S2) 


\section{SI Note 4}

Calculation of $\mathrm{K}_{e q},\left[\mathrm{Ag}^{+}\right]_{e q}$ and [base $]_{e q}$

$\mathrm{Ag}^{+}+2 \mathrm{Base} \rightleftarrows \mathrm{Ag}(\text { Base })_{2}^{+}$

1. Determine $K_{e q}$

$\left[\mathrm{Ag}^{+}\right]_{\text {eq }}$ is determined from OCP measurements, $[\mathrm{Ag}]_{0}$ and $[\mathrm{base}]_{0}$ is the total concentration of $\mathrm{Ag}^{+}$and the base added into the solution. $K_{e q}$ can be calculated using the following equation $K_{\text {eq }}=\frac{\left[\text { Ag }\left(\text { Base }_{2}^{+}\right]\right.}{\left[\text {Ag }^{+}\right] \times[\text {Base }]^{2}}$

Because [base $]_{0}$ is 20 times that of $[\mathrm{Ag}]_{0}$, assume the concentration of the base does not change significantly upon binding

$[\text { base }]_{0}=[\text { base }]_{\mathrm{eq}}$

$[\mathrm{Ag}]_{0}=\left[\mathrm{Ag}^{+}\right]_{\mathrm{eq}}+\left[\mathrm{Ag}(\text { base })_{2}^{+}\right]_{\mathrm{eq}}$

(Equation S3)

$K_{e q}=\frac{[\mathrm{Ag}]_{0}-\left[\mathrm{Ag}^{+}\right]_{\mathrm{eq}}}{\left[\mathrm{Ag}^{+}\right]_{\mathrm{eq}} \times[\text { base }]_{0}{ }^{2}}$

(Equation S5)

2. Determine $\left[\mathrm{Ag}^{+}\right]_{\mathrm{eq}}$ and $[\text { base }]_{\mathrm{eq}}$ during the reduction process with known $K_{e q}$

During the reduction process, the concentration of bases is no longer in great excess compared with that of $\mathrm{Ag}^{+}\left([\mathrm{base}]_{0}:[\mathrm{Ag}]_{0}=2: 1\right)$. Herein, an additional mass balance is considered,

$[\mathrm{Ag}]_{0}=\left[\mathrm{Ag}^{+}\right]_{\mathrm{eq}}+\left[\mathrm{Ag}(\text { base })_{2}^{+}\right]_{\mathrm{eq}}$

$[\text { base }]_{0}=[\text { base }]_{\mathrm{eq}}+2\left[\operatorname{Ag}(\text { base })_{2}^{+}\right]_{\mathrm{eq}}$

(Equation S6)

$K_{e q}=\frac{\left[\mathrm{Ag}(\text { base })_{2}^{+}\right]_{\mathrm{eq}}}{\left[\mathrm{Ag}^{+}\right]_{\mathrm{eq}} \times[\text { base }]_{\mathrm{eq}}}$

Based on the above equations, the values for $\left[\mathrm{Ag}^{+}\right]_{\mathrm{eq}}$ and $[\mathrm{base}]_{\mathrm{eq}}$ are difficult to be solved mathematically, but can be solved by an exhaustive algorithm. To repeat the same calculation for a series value of $[\mathrm{Ag}]_{e q}$ and [base $]_{\mathrm{eq}}$, we used a Macro in Excel that can perform goal seek in multiple cells. The calculations were performed for $\mathrm{Ag}^{+}$kinetic data for all DNA sequences both in the absence and presence of seeds. The average values of $[\mathrm{Ag}]_{e q}$ and $[\mathrm{base}]_{\mathrm{eq}}$ for the time scale in corresponding kinetic curves in Fig. 3 and Fig. $\mathbf{4}$ are listed in Table S1. Percent error is calculated by dividing the standard deviation by $[\mathrm{Ag}]_{0}$ or $[\text { base }]_{0}$.

Table S1. Average values of $[\mathrm{Ag}]_{e q}$ and $[\mathrm{base}]_{\mathrm{eq}}$ in the $\mathrm{Ag}^{+}$reduction processes with different DNA sequences

\begin{tabular}{|l|l|l|l|l|l|l|}
\hline & \multicolumn{2}{|c|}{ C20 } & \multicolumn{2}{c|}{ A20 } & \multicolumn{2}{c|}{ T20 } \\
\cline { 2 - 7 } & No seed & With seed & No seed & With seed & \multicolumn{1}{c|}{ No seed } & With seed \\
\hline [Ag $\left.^{+}\right]_{\text {eq }}$ & $0.57 \mu \mathrm{M}$ & $1.02 \mu \mathrm{M}$ & $6.83 \mu \mathrm{M}$ & $0.48 \mu \mathrm{M}$ & $164.00 \mu \mathrm{M}$ & $26.14 \mu \mathrm{M}$ \\
& $\pm 0.46 \%$ & $\pm 0.83 \%$ & $\pm 1.65 \%$ & $\pm 0.75 \%$ & $\pm 7.26 \%$ & $\pm 12.11 \%$ \\
\hline [base $_{\text {eq }}$ & $38.20 \mu \mathrm{M}$ & $108.21 \mu \mathrm{M}$ & $13.10 \mu \mathrm{M}$ & $122.65 \mu \mathrm{M}$ & $366.10 \mu \mathrm{M}$ & $394.26 \mu \mathrm{M}$ \\
& $\pm 2.46 \%$ & $\pm 26.56 \%$ & $\pm 0.78 \%$ & $\pm 19.12 \%$ & $\pm 0.64 \%$ & $\pm 2.52 \%$ \\
\hline
\end{tabular}

The standard deviations for $\left[\mathrm{Ag}^{+}\right]_{\text {eq }}$ with $\mathrm{C} 20$ and A20 are relatively small compared with that of T20, which agrees with the stronger binding of $\mathrm{C} 20$ and $\mathrm{A} 20$ towards $\mathrm{Ag}^{+}$. If we consider DNA - $\mathrm{Ag}^{+}$complex as a buffer system, the variation of $\mathrm{Ag}^{+}$during the reduction process will be affected by $\mathrm{Ag}^{+} / \mathrm{DNA}-\mathrm{Ag}^{+}$equilibrium. A20 and C20 demonstrated superior buffering 
capability compared with that of T20. Herein, in all the kinetic models with A20 and C20, $\left[\mathrm{Ag}^{+}\right]_{\mathrm{eq}}$ is assumed to be a constant throughout the reduction process. In contrast, $\left[\mathrm{Ag}^{+}\right]_{\mathrm{eq}}$ varies significantly in the presence of T20 due to the weak buffering effect. Therefore, $\left[\mathrm{Ag}^{+}\right]_{\mathrm{eq}}=$ $\frac{\left[\mathrm{Ag}^{+}\right]_{\text {total }}}{1+\mathrm{K}_{\text {eq }}[\text { Base }]_{\text {eq }}^{2}}(11)$ is used to account for the change of the $\mathrm{Ag}^{+}$in the reduction process with T20. [base] eq is assumed to be a constant in equation (11) because the standard deviation of [base $]_{\text {eq }}$ is much smaller than that of $\left[\mathrm{Ag}^{+}\right]_{\text {eq }}$ as shown in Table S1.

\section{SI Note 5}

A20 and C20-mediated $\mathrm{Ag}^{+}$reduction without preformed seed

One step analysis

$-\frac{d[\operatorname{Red}]}{d t}=k_{1}\left[\mathrm{Ag}^{+}\right]_{e q}[\mathrm{Red}]=k_{1}^{\prime}[\mathrm{Red}]$

(Equation S7)

Let $k_{1}^{\prime}=k_{1}\left[\mathrm{Ag}^{+}\right]_{\text {eq }}, k_{2}^{\prime}=k_{2}\left[\mathrm{Ag}^{+}\right]_{e q}$

$\left[\mathrm{Ag}^{+}\right]_{e q}$ for $\mathrm{A} 20$ is $6.83 \mu \mathrm{M}$, for $\mathrm{C} 20$ is $0.57 \mu \mathrm{M}$ (SI Note 4 and Table S1)

$-\frac{d[\mathrm{Red}]}{d t}=k_{1}^{\prime}$ [Red]

$\int_{[\text {Red }]_{O}}^{[\text {Red }]}-\frac{d[\text { Red }]}{k_{1}^{\prime}[\text { Red }]}=\int_{0}^{t} d t$

$\ln \frac{[\text { Red }]_{0}}{[\text { Red }]}=k_{1}^{\prime} t$

Rearrange the equation

$[$ Red $]=[\text { Red }]_{0} \exp ^{-k_{1}^{\prime} t}$

(Equation S8)

Two step analysis:

$-\frac{d[\text { Red }]}{d t}=k_{1}\left[\mathrm{Ag}^{+}\right]_{e q}[\mathrm{Red}]+k_{2}\left[\mathrm{Ag}^{+}\right]_{e q}[\operatorname{Red}]\left[\mathrm{Ag}^{0} \mathrm{n}\right]$

(Equation S9)

Let $k_{1}^{\prime}=k_{1}\left[\mathrm{Ag}^{+}\right]_{\text {eq }}, k_{2}^{\prime}=k_{2}\left[\mathrm{Ag}^{+}\right]_{e q}$

$\left[\mathrm{Ag}^{+}\right]_{e q}$ for $\mathrm{A} 20$ is $6.83 \mu \mathrm{M}$, for $\mathrm{C} 20$ is $0.57 \mu \mathrm{M}$ (SI Note 4 and Table S1)

$-\frac{d[\text { Red }]}{d t}=k_{1}^{\prime}[\operatorname{Red}]+k_{2}^{\prime}[\operatorname{Red}] 2\left([\operatorname{Red}]_{0}-[\operatorname{Red}]\right)$

$\int_{[\text {Red }]_{0}}^{[\text {Red }]}-\frac{d[\text { Red }]}{[\text { Red }]\left(k_{1}^{\prime}+2 k_{2}^{\prime}\left([\text { Red }]_{0}-[\text { Red }]\right)\right)}=\int_{0}^{t} d t$

$\mathrm{t}=\frac{\ln \left(\left(2 k_{2}^{\prime}\left([\mathrm{Red}]_{0}-[\mathrm{Red}]\right)+k_{1}^{\prime}\right)[\mathrm{Red}]_{0}\right)-\ln \left(k_{1}^{\prime}[\mathrm{Red}]\right)}{2 k_{2}^{\prime}[\mathrm{Red}]_{0}+k_{1}^{\prime}}$

(Equation S10) 

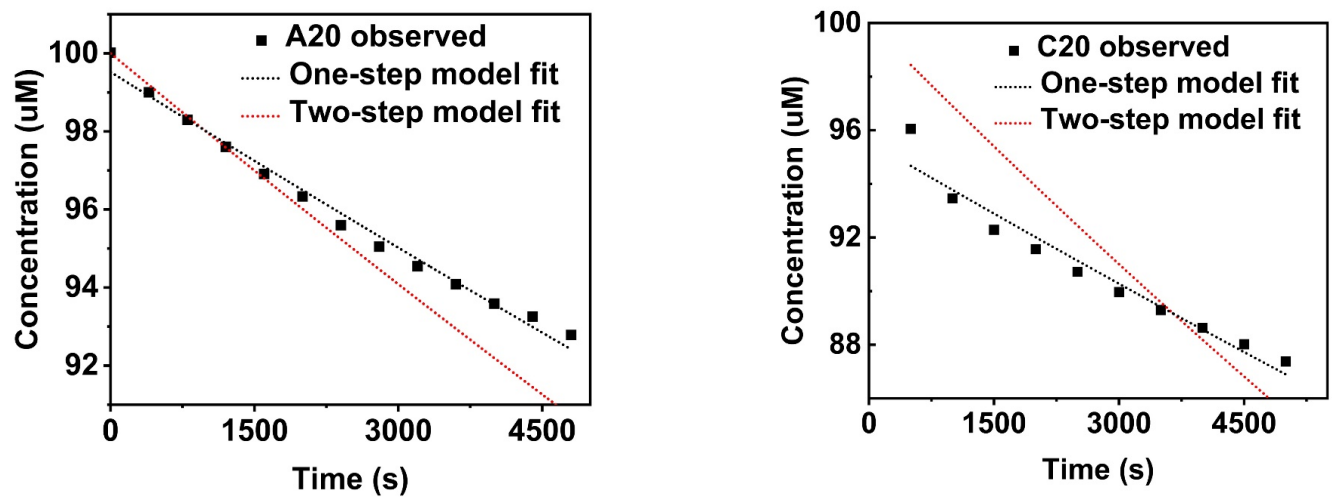

Figure S6. One-step and Two-step model fitting for reduction of Ag precursor by ascorbic acid in the presence of A20 and C20 without preformed seeds.

\section{SI Note 6}

T20-mediated $\mathrm{Ag}^{+}$reduction with preformed seed: two step analysis

$-\frac{d[A A(r e)]}{d t}=k_{1}\left[\mathrm{Ag}^{+}\right]_{\mathrm{eq}}[\operatorname{Red}]+k_{2}\left[\mathrm{Ag}^{+}\right]_{\mathrm{eq}}[\operatorname{Red}]\left[\mathrm{Ag}^{0}{ }_{\mathrm{n}}(\mathrm{seed})\right]$

(Equation S11)

where $\left[\mathrm{Ag}^{0}\right.$ (seed)] is the total concentration of the surface atoms on the seed. It was assumed $\left[\mathrm{Ag}_{\mathrm{n}}{ }_{\mathrm{n}}(\mathrm{seed})\right]$ does not change over time, because the overall size of the final particle was similar to that of the seed. ${ }^{1}\left[\mathrm{Ag}_{\mathrm{n}}^{0}\right.$ (seed)] was calculated to be $4.5 \mu \mathrm{M}$ using the method described previously. ${ }^{3}$ The concentration of available surface sites for Ag atom deposition is less than the total concentration of surface atoms due to the surface passivation by DNA. The ligand replacement assay in the remaining active surface sites was determined by the following equations:

$$
\begin{aligned}
& {\left[\mathrm{Ag}^{0}{ }_{\mathrm{n}}(\mathrm{seed})\right]_{\mathrm{T} 20}=4.5 \mu \mathrm{M} \times 98.71 \%=4.4 \mu \mathrm{M}} \\
& {\left[\mathrm{Ag}^{+}\right]_{e q}=\frac{\left[\mathrm{Ag}^{+}\right]_{t}}{1+K_{e q}[D N A]_{e q}^{2}}}
\end{aligned}
$$

According to the stoichiometry of the reaction, we can obtain the following relationship:

$\mathrm{d}\left[\mathrm{Ag}^{+}\right]_{\mathrm{t}}=2 \mathrm{~d}[\mathrm{Red}]_{\mathrm{t}}$

where the initial $\mathrm{Ag}^{+}$concentration $\left[\mathrm{Ag}^{+}\right]_{0}$ is equal to $2[\mathrm{Red}]_{0}$, and $\left[\mathrm{Ag}^{+}\right]_{\mathrm{t}}$ is equal to $2[\mathrm{Red}]_{\mathrm{t}}$. For simplicity, the subscript $t$ was omitted in the following equations:

$$
\begin{aligned}
& -\frac{d[\mathrm{Red}]}{d t}=k_{1} \frac{2[\mathrm{Red}]}{1+K_{e q}[\text { base }]_{e q}^{2}}[\mathrm{Red}]+k_{2} \frac{2[\mathrm{Red}]}{1+K_{e q}[\text { base }]_{e q}^{2}}[\mathrm{Red}]\left[\mathrm{Ag}^{0} \mathrm{n}(\mathrm{seed})\right] \\
& \text { Let } k_{1}^{\prime}=\frac{k_{1}}{1+K_{e q}[\text { base }]_{e q}^{2}}, \quad k_{2}^{\prime}=\frac{k_{2}}{1+K_{e q}[\text { base }]_{e q}^{2}}, \quad[\text { base }]_{\mathrm{eq}}=394.26 \mu \mathrm{M}(\text { SI Note } 4 \text { and Table S1) }
\end{aligned}
$$$$
[\text { Red }]=\frac{1}{2\left(k_{1}^{\prime}+k_{2}^{\prime}\left[\mathrm{Ag}_{\mathrm{n}}^{\mathrm{o}}(\mathrm{seed})\right]\right) \mathrm{t}+1 /[\operatorname{Red}]_{0}}
$$ 


\section{SI Note 7}

A20 and C20-mediated $\mathrm{Ag}^{+}$reduction with preformed seed: two-step process

For a two-step process, the reaction can be determined by the following equations:

$-\frac{d[A A(r e)]}{d t}=k_{1}\left[\mathrm{Ag}^{+}\right]_{\mathrm{eq}}[\operatorname{Red}]+k_{2}\left[\mathrm{Ag}^{+}\right] \mathrm{eq}[\operatorname{Red}]\left[\operatorname{Ag}^{0} \mathrm{n}(\right.$ seed $\left.)\right]$

(Equation S14)

$[\mathrm{Red}]=[\mathrm{Red}]=[\operatorname{Red}]_{0} \exp ^{-\left(k_{1}^{\prime}+k_{2}^{\prime}\left[\operatorname{Ag}_{n}^{0}(\text { seed })\right]\right) t}$

(Equation S15)

where $k_{1}^{\prime}=k_{1}\left[\mathrm{Ag}^{+}\right]_{e q}$ and $k_{2}^{\prime}=k_{2}\left[\mathrm{Ag}^{+}\right]_{e q} \cdot\left[\mathrm{Ag}^{+}\right]_{e q}$ is $0.48 \mu \mathrm{M}$ for A20 and $1.02 \mu \mathrm{M}$ for C20 (SI Note 4 and Table S1). $\left[\mathrm{Ag}^{0}{ }_{\mathrm{n}}(\mathrm{seed})\right]_{\mathrm{A} 20}$ is equal to $4.5 \mu \mathrm{M} \times 95.63 \%$ or $4.3 \mu \mathrm{M}$, and $\left[\mathrm{Ag}^{0}{ }_{\mathrm{n}}(\mathrm{seed})\right]_{\mathrm{C} 20}$ is equal to $4.5 \mu \mathrm{M} \times 93.77 \%$ or $4.2 \mu \mathrm{M}$.

In this two-step analysis, the surface reduction reaction on the nuclei was not included in the calculations because in the reduction without the seed, the surface reduction on the just-formed nuclei does not contribute to the overall reduction rate. As explained in SI Note 5, the growth curves in the presence of A20 and C20 were fitted with both one- and two-step models. The twostep model significantly deviated from the experimental data $\left(\mathrm{R}^{2}\right.$ value is 0.79 for $\mathrm{A} 20$ and 0.26 for C20), whereas the one-step model matched well with the kinetic results with the $\mathrm{R}^{2}$ value of 0.99 for A20 and 0.95 for $\mathrm{C} 20$. The $k_{1}$ ' value derived from the one-step model was $1.53 \times 10^{-5} \mathrm{~s}^{-}$ ${ }^{1} \mu \mathrm{M}^{-1}$ for A20 and $1.37 \times 10^{-5} \mathrm{~s}^{-1} \mu \mathrm{M}^{-1}$ for C20. Unlike the two-step model, the one step-model did not involve the surface reduction for either A20- or C20-mediated reduction. The result from the model fitting suggested that even though there existed self-nucleation in the seed-mediated synthesis (Fig. 1g), those nuclei did not lead to additional surface reduction reaction. The inhibition of surface reduction on the nuclei could originate from passivating the surface of the nuclei by DNA. The formed nuclei are much smaller in size $(3.0 \pm 1.0 \mathrm{~nm})$ than the nanocrystals formed with the seed $(74.8 \pm 3.4 \mathrm{~nm})$, thus have larger surface-to-volume ratio and higher surface energy. The active surface sites on the nuclei therefore might be passivated to a larger extent than the seeded crystals due to their interaction with DNA. Formation of smaller nanoparticles with polyA DNA sequences was also previously observed in the seed-mediated synthesis of Au NPs. ${ }^{4}$ This phenomenon appears to be common among different systems, which suggests adenosine should stabilize small nanocrystals, presumably due to its ability to bind to the high index facets. ${ }^{5}$

\section{SI Note 8}

C20-mediated $\mathrm{Ag}^{+}$reduction with preformed seed: one step process

$-\frac{d[\text { Red }]}{d t}=k_{1}\left[\mathrm{Ag}^{+}\right]_{e q}[\mathrm{Red}]=k_{1}^{\prime}[\mathrm{Red}]$

(Equation S15)

$\left[\mathrm{Ag}^{+}\right]_{e q}$ for $\mathrm{C} 20$ is $1.02 \mu \mathrm{M}$ (SI Note 4 and Table S1)

$$
\begin{aligned}
& \int_{[\text {Red }]_{0}}^{[\text {Red }]}-\frac{d[\text { Red }]}{[\text { Red }]}=\int_{0}^{t} d t \\
& \ln \frac{[\text { Red }]_{0}}{[\text { Red }]}=k_{1}^{\prime} \mathrm{t} \\
& \text { Rearrange } \\
& {[\text { Red }]=[\text { Red }]_{0} e \exp ^{-k_{1}^{\prime} t}}
\end{aligned}
$$




\section{SI Note 9}

Fluorescence-based DNA quantification method using ME replacement

Experiments of DNA quantification were performed using fluorescein-labeled DNA to replace unlabeled DNA for the nanoparticle growth. The formed particles were washed by water and then centrifuged to remove the excess DNA in the solution. Each batch of synthesized particles was separated into two equal portions. Half of the particles was added to $1 \mathrm{ml}$ of $10 \mathrm{mM} \mathrm{KCN}$ to etch the particles and release DNA. The reaction took $6 \mathrm{~h}$ to complete. The concentration of DNA was determined through fluorescence measurements of the KCN solution. The concentration of DNA attached on the particles is designated as $\mathrm{C}_{\text {total }}$. The other half of the particles was dispersed in 1 $\mathrm{ml}$ of $14 \mathrm{mM} \mathrm{ME}$ for ligand exchange. The reaction was left for 12 hours for completion. The particles were thoroughly washed to remove the excess ME after the ligand exchange. The washed particles were redispersed in $1 \mathrm{ml}$ of $10 \mathrm{mM} \mathrm{KCN}$ for etching particles and release DNA. The reaction was left for $6 \mathrm{~h}$ for completion. The concentration of DNA was determined through fluorescence measurements of the etched solution. The concentration of the original DNA on the particles after ligand exchange is herein designated as $\mathrm{C}_{\mathrm{un}}$. The concentration of replaced DNA $\left(\mathrm{C}_{\mathrm{re}}\right)$ was calculated by the following equation:

$\mathrm{C}_{\mathrm{re}}=\mathrm{C}_{\text {total }}-\mathrm{C}_{\text {un }}$

(Equation S16)

The percentage of replacement $\%$ Re could be calculated based on the following equation:

$\% \operatorname{Re}=\mathrm{C}_{\mathrm{re}} / \mathrm{C}_{\text {total }} \times 100 \%$

We performed the quantitative analysis for both Ag shells and Au cores. The percentage of replacement is listed in Table S2.

Table S2. Percentage of DNA on both Ag shells and Ag cores replaced by ME

\begin{tabular}{|c|c|c|c|}
\hline$\% \operatorname{Re}$ & C20 & A20 & T20 \\
\hline Ag shell & $93.77 \pm 1.27 \%$ & $95.63 \pm 0.31 \%$ & $98.71 \pm 0.40 \%$ \\
\hline Au core & $92.12 \pm 3.26 \%$ & $96.98 \pm 2.05 \%$ & $98.33 \pm 1.30 \%$ \\
\hline
\end{tabular}

The percentage of DNA replacement on both Ag shells and Au cores follows the order: C20<A20 $<$ T20, which indicates the similar order on the available active sites on these two types of nanostructures. Ag and $\mathrm{Au}$ are in the same group in the periodic table, and both crystals have the FCC structures with similar lattice constants. ${ }^{11}$ The similarity in the trend of DNA binding can be ascribed to the similar physicochemical properties between Ag and Au. The data indicates that the diffusivity of Ag atoms on the Au core follows the same trend as that on the Ag shell, which results in similar deposition and diffusion patterns. Note that all the relative DNA binding affinity were compared with ME. We could compare the relative affinity across different sequences but we could not compare the binding affinity of the same sequence to both Ag shell and Au core, because the binding affinity of ME to the Ag shell and the Au core might be different. However, such discrepancy does not affect the conclusion drawn from the data because the deposition and diffusion of Ag atoms on the Ag crystal surfaces are the determining factors in the analysis. This method is reasonable because after the first layer was deposited onto the Au seed (either complete 
or partial coverage), Ag adatoms would be preferably deposited on the formed Ag layers. Therefore, the following process should be deposition of Ag on the surface of the same metal.

\section{SI Note 10}

Prior to each synthesis, decahedra seeds were washed by water and centrifuged at $6 \mathrm{k}$ rpm for 5 min for three times to remove as much benzyldimethylhexadecylammonium chloride (BDAC) as possible, though some BDAC is necessary to keep the colloidal stability of the seeds. The aggregation of the seed is usually irreversible because agglomeration is energetically favored. If BDAC is removed too much, aggregation of seeds can happen irreversibly, even after adding fresh DNA. Therefore, the washing procedure of decahedral seeds was optimized to maintain a minimum level of BDAC on the surface to maintain the colloidal stability. The $\zeta$ potential of $\mathrm{Au}$ decahedra after the washing step was determined to be $+8.36 \pm 0.11 \mathrm{mV}$, which demonstrates the BDAC ligand provides the positive charge necessary to maintain the colloidal stability of the particles. Meanwhile the value of the potential also suggests the ligand is of minimum amount. Upon addition of negatively charged DNA, the $\zeta$ potential of the particles was significantly reversed, which indicates the successful adsorption of DNA onto the particles.

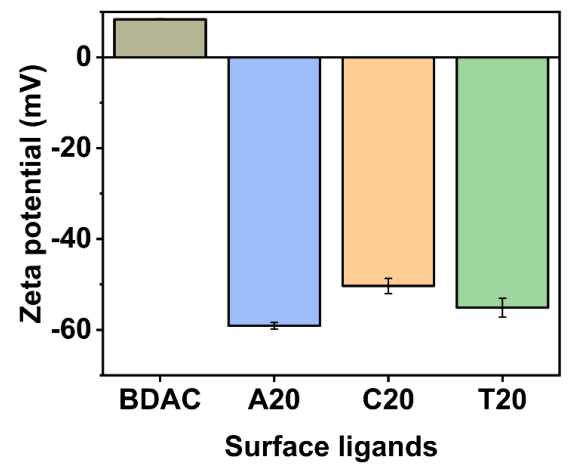

Figure S7. $\zeta$ potential of Au decahedra solution immediately after washing with BDAC, followed by adding different DNA sequences.

\section{Reference}

1. Watzky, M. A.; Finke, R. G., Transition Metal Nanocluster Formation Kinetic and Mechanistic Studies. A New Mechanism When Hydrogen Is the Reductant: Slow, Continuous Nucleation and Fast Autocatalytic Surface Growth. Journal of the American Chemical Society 1997, 119 (43), 10382-10400.

2. Stathis, E., Determination of silver with ascorbic acid. Analytical Chemistry 1948, 20 (3), 271-271.

3. $\quad$ Yang, T. H.; Peng, H. C.; Zhou, S.; Lee, C. T.; Bao, S.; Lee, Y. H.; Wu, J. M.; Xia, Y., Toward a Quantitative Understanding of the Reduction Pathways of a Salt Precursor in the Synthesis of Metal Nanocrystals. Nano Lett 2017, 17 (1), 334-340.

4. Satyavolu, N. S. R.; Tan, L. H.; Lu, Y., DNA-Mediated Morphological Control of Pd-Au Bimetallic Nanoparticles. Journal of the American Chemical Society 2016, 138 (50), 1654216548 . 
5. Tan, L. H.; Yue, Y.; Satyavolu, N. S. R.; Ali, A. S.; Wang, Z.; Wu, Y.; Lu, Y., Mechanistic Insight into DNA-Guided Control of Nanoparticle Morphologies. Journal of the American Chemical Society 2015, 137 (45), 14456-14464.

6. Oswald, W., Studien uber die Bildung und Umwandlung fester Korper. Z. Phys. Chem 1897, 22, 289-330.

7. Kahlweit, M., Ostwald ripening of precipitates. Advances in Colloid and Interface Science 1975, 5 (1), 1-35.

8. Njoki, P. N.; Luo, J.; Kamundi, M. M.; Lim, S.; Zhong, C.-J., Aggregative Growth in the Size-Controlled Growth of Monodispersed Gold Nanoparticles. Langmuir 2010, 26 (16), 1362213629.

9. $\quad$ Richards, V. N.; Rath, N. P.; Buhro, W. E., Pathway from a Molecular Precursor to Silver Nanoparticles: The Prominent Role of Aggregative Growth. Chemistry of Materials 2010, 22 (11), 3556-3567.

10. Woehl, T. J.; Park, C.; Evans, J. E.; Arslan, I.; Ristenpart, W. D.; Browning, N. D., Direct Observation of Aggregative Nanoparticle Growth: Kinetic Modeling of the Size Distribution and Growth Rate. Nano Letters 2014, 14 (1), 373-378.

11. Davey, W. P., Precision Measurements of the Lattice Constants of Twelve Common Metals. Physical Review 1925, 25 (6), 753-761. 